\title{
EL ESTADO DE NECESIDAD CIVIL ANTE LA PANDEMIA DEL COVID-19: UNA APROXIMACIÓN CRÍTICA
}

\section{THE STATE OF CIVIL NECESSITY IN THE FACE OF THE COVID-19 PANDEMIC: A CRITICAL APPROACH}

* Profesor de Derecho Civil de la Universidad Nacional Mayor de San Marcos, de la Universidad Peruana de Ciencias Aplicadas y de la Universidad Tecnológica del Perú. Profesor Principal de la Academia de la Magistratura. Amicus Curiae de las Salas Civiles reunidas de la Corte Suprema de Justicia. Consultor jurídico y árbitro.

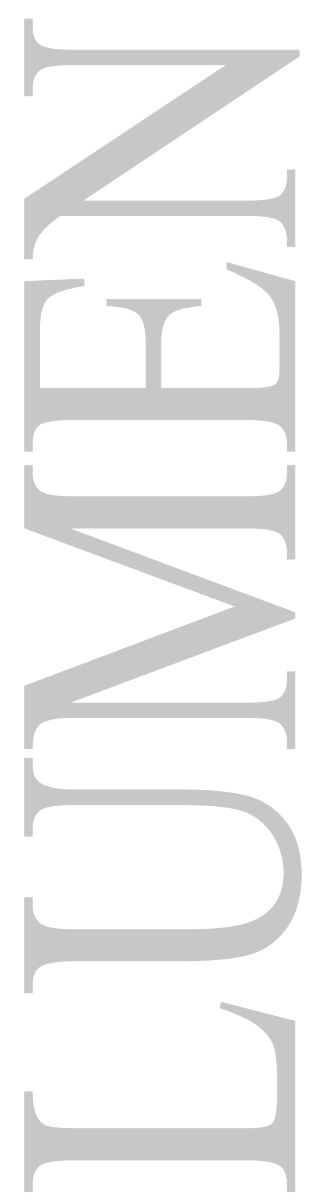




\title{
EL ESTADO DE NECESIDAD CIVIL ANTE LA PANDEMIA DEL COVID-19: UNA APROXIMACIÓN CRÍTICA
}

\author{
THE STATE OF CIVIL NECESSITY IN THE FACE OF THE COVID-19 PANDEMIC: \\ A CRITICAL APPROACH
}

Fort Ninamancco Córdova.

\begin{abstract}
RESUMEN
El presente trabajo busca esbozar un análisis crítico sobre la aplicabilidad del estado de necesidad civil, previsto en el inciso 3 del artículo 1971 del Código Civil, frente al contexto de crisis socioeconómica generada por la pandemia del Covid-19. Siendo así, tomando como referencia a planteamientos doctrinarios europeos, el autor se aproxima críticamente a la doctrina nacional y a la normativa de nuestro Código Civil, estableciendo algunas directrices que deben tomarse en cuenta al momento de evaluar tal aplicabilidad, misma que ha venido siendo descuidada en los debates civilistas que se han dado a propósito de la pandemia.
\end{abstract}

\section{PALABRAS CLAVE}

Estado de necesidad, covid 19, norma, código civil.

\begin{abstract}
This work seeks to outline a critical analysis on the applicability of the state of civil necessity, provided for in paragraph 3 of article 1971 of the Civil Code, in the context of the socio-economic crisis generated by the Covid-19 pandemic. Thus, taking as a reference to European doctrinal approaches, the author critically approaches the national doctrine and the regulations of our Civil Code, establishing some guidelines that must be taken into account when evaluating such applicability, which has been neglected in the civilistas debates that have occurred regarding the pandemic.
\end{abstract}

\section{KEY WORDS}

State of necessity, covid 19, norm, civil code.

\section{INTRODUCCIÓN:}

Bien sabido es que la pandemia del Covid-19 está significando una crisis social y económica sin precedentes. Al respecto, se ha informado lo siguiente con respecto a nuestra región: La pandemia ha provocado una conmoción en las sociedades y economías (...) A medida en que la pandemia se propaga en la región, su caracterización como crisis sanitaria, económica y social es cada vez más evidente. La dimensión y la duración de sus efectos, si bien difíciles de cuantificar debido a la incertidumbre, comienzan a ser percibidas con claridad. Será la causa de la mayor crisis económica y social de la región en décadas, con efectos muy negativos en el empleo, el combate a la pobreza y la reducción de la desigualdad (CEPAL, 2020, pp. 7 y 8). Si nos referimos a las personas naturales, puede decirse que un gran sector de la población ha visto seriamente mermados sus ingresos económicos, que ya de por sí podían ser un tanto exiguos. Esto conlleva, obviamente, a que estas personas centren sus esfuerzos en cubrir sus necesidades básicas, dejando de lado otra clase de necesidades o asuntos. La debida atención de tales necesidades, en un contexto socioeconómico tan crítico, es algo que puede ya de por sí resultar difícil. Es una simple cuestión de sobrevivencia. Otro tanto ocurre con las personas jurídicas, en tanto se hayan encontrado vinculadas a las actividades económicas que fueron suspendidas por las medidas de lucha contra la pandemia. El cierre general de establecimientos y locales comerciales, que no prestan bienes y servicios "esenciales", ha provocado daños serios, si es que no el descalabro, de las MYPES. El efecto nocivo de la pandemia 
se agrava si se considera que las MYPES son un pilar decisivo para un sistema económico como el peruano. Y es que, según la CEPAL (2020):

La alta tasa de informalidad laboral de la región hace muy vulnerables a los trabajadores a los efectos de la pandemia y a las medidas para enfrentarla. La elevada participación de las pequeñas y medianas empresas en la creación del empleo (más del $50 \%$ del empleo formal) aumenta los efectos negativos, pues este sector ha sido duramente afectado por la crisis. (p. 14).

Entonces no solo las personas naturales, sino también las personas jurídicas -u organizaciones de personas no inscritas o sociedad irregulares, dada la informalidad que siempre ha caracterizado al tráfico económico y jurídico peruano- entrarán en una situación de lucha por subsistir. En tal sentido, se afirma lo siguiente:

Las empresas, independientemente de su tamaño, enfrentan importantes disminuciones de sus ingresos, dificultades para el acceso al crédito y un aumento en la probabilidad de insolvencia. Además, los trabajadores sufren un marcado deterioro en las condiciones laborales, empleo o ingresos que, sumado a lo anterior, lleva a un deterioro en la demanda agregada de los países y a aumentos en la pobreza (CEPAL, 2020, p. 14).

Ahora bien, es evidente que la pandemia está dejando muy golpeado el sistema de salud. Si antes de ella, el acceso a la salud adolecía de problemas y desigualdades en su acceso, pues de ahora en adelante ello podría ser mucho peor. De este modo, enfrentar un problema de salud que comprometa de forma grave la integridad física o la vida misma no solo podría ser más frecuente, sino también mucho más difícil de afrontar. Los más afectados económicamente por la pandemia, esto es la gran mayoría de la población latinoamericana, terminarán más expuestos no solo a la enfermedad del Covid-19, sino a otras enfermedades o complicaciones de salud (CEPAL, 2020, p. 6).

Pues bien, en lo que al Derecho Civil se refiere, corresponde ser consciente de que la aguda crisis generalizada del Covid-19 puede traducirse en la ocurrencia de daños y perjuicios derivados de actuaciones en "estado de necesidad", conforme a lo previsto en el inciso 3 del artículo 1971. En términos crudos, es muy probable que, en la lucha por subsistir a los embates de la pandemia en el plano socioeconómico, algunas personas (naturales o jurídicas) provoquen daños a sus semejantes y terminen justificando su accionar en la presencia de un "estado de necesidad". Veamos algunos supuestos:

a) Dada su inusitada pérdida de ingresos, el inquilino señala que no puede pagar la renta (o no puede pagarla de forma completa), porque de lo contrario su subsistencia peligraría. No tendría dinero suficiente para comer o comprar medicinas. De hecho, piénsese en el caso de un arrendatario que ha adquirido la enfermedad del Covid-19 y debe luchar cada día por conseguir oxígeno y medicamentos. Pagar la renta podría significarle una muerte segura.

b) Ese mismo inquilino, supóngase que es un independiente o-como gustan decir en Europaautónomo, debe cumplir ciertos contratos de prestación de servicios, ¿qué sucede si solo puede cumplir algunos, pues requiere tiempo para atender a su familia afectada por la enfermedad del Covid-19? El tiempo para cumplir todos los contratos lo tiene, solo que si hace esto, expone a su familia al riesgo de morir por la enfermedad.

c) Piénsese ahora en que uno de los clientes de dicho inquilino es una microempresa; esta, asolada por la crisis socioeconómica de la pandemia, también alega un "estado de necesidad" para no pagar la renta por su local comercial o no cumplir ciertos contratos con sus propios clientes. Pretende no cumplir o cumplir solo de forma parcial. Sostiene que si

d) procede a cumplir sin más tales compromisos, le espera el descalabro financiero. Si cumple, no sobrevive.

e) Por último, consideramos el caso de una persona que tiene a un precario poseyendo un 
inmueble de su propiedad. Sucede que un familiar directo de este propietario ha sido diagnosticado con la enfermedad del Covid-19 y no tiene donde pasar el confinamiento. Obviamente no puede llevarlo a su residencia. Por ende, procede a sacar del inmueble al precario, extrajudicialmente por supuesto, alegando encontrarse en "estado de necesidad".

f) Si no procedía de este modo, su familiar podía quedar desamparado y mucho más expuesto a los peligros pandémicos.

¿Es aplicable el inciso 3 del artículo 1971 a casos como los que se acaban de mencionar? ¿Hasta qué punto la severa crisis pandémica puede permitir la configuración del "estado de necesidad" previsto en la citada disposición legal?

Como es fácil notar, brindar respuestas afirmativas implica que el inquilino y la microempresa no asumirían responsabilidad civil por sus actos. No tendrían obligación de indemnizar por los daños y perjuicios que ocasionasen a sus contrapartes contractuales.

En las líneas que siguen me propongo establecer algunos lineamientos que deberían tenerse en cuenta al momento de dar respuestas a las interrogantes planteadas y, en general, siempre que se pretenda evaluar la aplicación del "estado de necesidad" en este contexto socioeconómico tan crítico que nos ha tocado vivir. Advierto, entonces, que no pretendo ser exhaustivo, sino tan solo contribuir en algo a las discusiones civilistas en torno a la pandemia, sobre todo en relación a una figura que ha venido siendo-injustamente, por cierto- soslayada en tales discusiones. Por ello, por ejemplo, no analizaré aquí la cuestión relativa a si el titular del bien sacrificado debe asumir o no los costos del daño que le tocó experimentar.

\section{El "estado de necesidad" previsto en el inciso 3 del artículo 1971 del Código Civil: consideraciones sobre la base de la doctrina nacional y extranjera.}

Recientemente, una importante doctrina nacional ha señalado que el "estado de necesidad" previsto en el inciso 3 del artículo 1971 es una de "las situaciones de irresponsabilidad (...) también denominadas como situaciones de daño necesario o daño justificado" (Fernández, 2019 p. 55). Se describe a la figura en estos términos "El estado de necesidad implica una situación objetiva en la cual la única posibilidad de conjurar el peligro inminente es mediante la afectación de un bien ajeno, no debiendo existir otra alternativa" (Fernández, 2019 p. 93).

Esta doctrina considera que existen tres requisitos para invocar el "estado de necesidad": i) debe presentarse un "riesgo potencial" de sufrir un daño que "debe calificar como imprevisible"; ii) el citado "riesgo potencial" debe entenderse como la inminencia del daño. Esto es, en términos cronológicos, como una "proximidad de sufrir un daño, de modo tal que no exista tiempo de conjurarlo sino únicamente con la afectación de un bien ajeno":

Debe presentarse una desproporcionalidad entre el valor del bien salvado y el valor del bien sacrificado". Sobre esto último, se precisa que "cuando se habla de la categoría de bien salvado puede tratarse de un bien económico o no, pero el bien sacrificado debe ser necesariamente económico (Fernández, 2019 p. 93).

Otra importante doctrina nos señala que "se suele definir al estado de necesidad como el sacrificio de un bien jurídicamente de inferior jerarquía en favor de un bien jurídicamente de superior jerarquía, frente a un peligro inminente". Señala, siguiendo a una autorizada doctrina italiana, que los elementos del estado de necesidad son: i) el daño que se busca evitar debe ser "grave", ii) la situación de peligro debe ser "inevitable" y iii) debe haber "la ausencia de un particular deber jurídico de exponerse al peligro". Se agrega que debe haber "notoria diferencia entre el bien sacrificado y el bien salvado" (Espinoza, 2013, pp. 140 y 141). 
Un ilustre autor peruano entiende que el estado de necesidad es la manifestación de un "derecho de dañar" que el sistema jurídico dispone ante una "circunstancia extraordinaria" (De Trazegnies, 2001, p. 212). El bien salvado debe ser "manifiestamente superior" al bien sacrificado. Esta doctrina parece entender, aunque se muestra disconforme frente a ello, que es posible apreciar que la idea de "solidaridad" inspira nuestra regulación del "estado de necesidad". Así, entiende que "el inciso 3 del artículo 1971 del Código Civil me autoriza a obligar al vecino a compartir mi riesgo y mi daño, porque le causo una merma en mí exclusivo provecho y no le indemnizo: así, yo no pierdo, pero él sí" (De Trazegnies, 2001, p. 222). Se advierte que, por lo general, el estado de necesidad "proviene de una situación de caso fortuito", pero puede también haber "sido creado por un tercero" (De Trazegnies, 2001, p. 225).

En la doctrina francesa, se explica que el "estado de necesidad" fue obra de la jurisprudencia, pues el Código napoleónico no la contempló. Al respecto, se dice que el "estado de necesidad se corresponde con la situación de quien debe decidir atentar contra la persona o propiedad de otro para evitar un mal o grave peligro para sí mismo o para otros" (BRUN, 2016, p. 311). Se apela a una terminología más amplia, y se habla de "interés"; de este modo, se puede aceptar que el estado de necesidad tiene lugar cuando el "interés sacrificado es mucho menor que el interés salvaguardado" (BRUN, 2016, p. 312).

El Código Civil alemán, BGB, contiene dos preceptos que están vinculados a la doctrina del "estado de necesidad". Por un lado, el $§$ 228, que permite la destrucción de cosas ajenas para salvarse a uno mismo, o a otros, de un peligro de daño procedente de tales cosas. Se exige que dicho daño "guarde proporción" con las cosas que se tienen que destruir. Por otro lado, el § 904, que establece que el propietario de un cosa debe soportar el hecho dañoso sobre la misma, que sirva para evitar un daño o riesgo de daño que también sea "desproporcionadamente mayor".

Como bien ha sido advertido dentro como fuera de Alemania, el radio de acción del $\S 228$ es bastante restringido, pues no contempla supuestos donde el peligro de daño no deriva de la cosa que se tiene que destruir o afectar para conseguir el salvamento (Westermann, Gursky Y Eickmann, 2007, p. 307; Bianca, 2002, p. 663). Por esta razón, la doctrina alemana ha procedido a ensanchar los alcances del § 904.

En efecto, se postula que el $\S 228$ hace referencia a un "estado de necesidad defensivo", en tanto "que se refiere a la defensa frente a un riesgo procedente de una cosa"; en cambio, el $\S 904$ se refiere a un "estado de necesidad agresivo" que importa un "deber de soportar injerencias" o "deber de tolerancia del propietario que no ha participado en la creación del riesgo". Se trata de un deber que no se circunscribe al derecho de propiedad, sino que se debe extender-vía analogía- "a otros derechos reales absolutos" (Westermann, Westermann, Gursky Y Eickmann, 2007, pp. 108 y 307).

Se propone un ejemplo del "estado de necesidad agresivo": una persona, atacada por un "fiero perro", no tiene más remedio que arrancar una estaca de una valla ajena para golpear al perro y así conseguir defenderse. El dueño de la valla "tiene un deber de tolerancia". Se agrega lo siguiente:

El peligro que amenazaba al que actuó - un posible daño corporal- era desproporcionadamente mayor que el daño a la valla. La vida y la salud de una persona son siempre más valiosas que los bienes valorables en dinero; en caso de simples daños patrimoniales, la decisión depende de una valoración cuantitativa. Consiguientemente, la ruptura de la valla fue conforme a derecho. (Westermann, Westermann, Gursky Y Eickmann, 2007, p. 308).

Por último, en Italia, se entiende que: 
El estado de necesidad es una situación de hecho que constriñe al sujeto a realizar un acto lesivo del derecho ajeno a fin de salvarse a sí o a otros del peligro actual de un daño grave a la persona, no causado voluntariamente ni tampoco evitable de otro modo. (Bianca, 2002, p. 663).

Así, se indica que el estado de necesidad "hace imposible respetar el derecho ajeno", pues implica un "sacrificio superior" al que se requiere por "el normal deber de diligente salvaguardia de los intereses tutelados en la vida social" (Bianca, 2002, p. 665).Se tiene que distinguir entre el estado de necesidad que comporta el sacrificio de un "derecho de la personalidad ajeno", del estado de necesidad que comporta el sacrificio de un "derecho económico ajeno". La primera hipótesis siempre se entenderá como "un hecho antijurídico", lo que no ocurre con la segunda, pues en esta sí cabe excluir la antijuridicidad (Bianca, 2002, p. 667).

El Derecho italiano reduce el radio de acción del estado de necesidad a la protección de la persona, frente a un riesgo de daño que:

Puede derivar de un hecho del hombre o de un hecho natural. En todo caso, debe tratarse de un perjuicio serio, tal que pueda justificar o hacer socialmente tolerable la invasión de la esfera jurídica ajena a fin de obtener el salvamento. (Bianca, 2002, p. 669).

A diferencia del nuestro Código Civil, el artículo 2045 del Código Civil italiano sí hace referencia que el peligro inminente no debe haber sido obra de la voluntad del sujeto necesitado. Si el peligro de daño ha tenido lugar "voluntaria o culposamente" por el necesitado, no cabe hablar de estado de necesidad. Si cabe, por el contrario, si tal peligro ha sido provocado por dolo o culpa de un tercero (Bianca, 2002, p. 670).

El sacrificio del bien ajeno debe ser "instrumental" para el salvamento de la persona del necesitado. O sea, el daño al bien ajeno debe "servir para conjurar el peligro". Es más, si el necesitado incurre en un error no culpable ("error excusable") sobre la idoneidad del hecho dañoso para lograr el salvamento, de todos modos puede tener lugar el "estado de necesidad" (Bianca, 2002, p. 671).

\section{Estado de necesidad e incumplimiento contractual: la doctrina alemana de la inexigibilidad y del "riesgo de la realidad social común".}

El incumplimiento de un contrato puede ser un tipo de acto de sacrificio de un "bien", en el marco del "estado de necesidad". En efecto, el incumplimiento es una lesión al derecho de crédito, que puede provocar daños en el acreedor contractual, lo que activa la responsabilidad civil por inejecución de obligaciones. (Torres, 2014, pp. 895 y 896).

Es interesante notar como la doctrina europea maneja un enfoque amplio en este aspecto. La francesa, como se recordará, ni siquiera apela al concepto de bien, sino de "interés" sacrificado, que sin duda es más amplio. La italiana refiere que cualquier "derecho económico" puede ser materia del acto de sacrificio. La alemana, de igual forma, ha consagrado una interpretación amplia y una aplicación analógica del § 904 del BGB, para sostener que el "estado de necesidad" puede implicar el sacrificio de otros derechos reales, no solo del derecho de propiedad.

¿Debemos entender, entonces, que en Alemania no cabe invocar el sacrificio de derechos de crédito, sino solo de derechos reales, en el "estado de necesidad"? ¿La figura del estado de necesidad en Alemania, entonces, sería mucho más estrecha que en Francia o Italia? No lo creo, por dos razones. Por un lado, como expliqué en otra sede, un prestigioso sector de la doctrina alemana ha dejado establecido que los derechos de crédito, tal como ocurre con los derechos reales, tienen una tutela o protección "absoluta" (Ninamancco, 2013, pp. 141-144). Ergo, el derecho 
del acreedor también puede ser un "bien sacrificado" en un caso de "estado de necesidad", conforme a la promovida aplicación analógica del § 904 del BGB; por otro lado, como veremos en breve, la doctrina alemana ha apelado a la idea de "buena fe" para "justificar" incumplimientos en aras de proteger bienes especialmente valiosos. De este modo, al final del día, sí cabe el sacrificio de derechos de crédito.

Por lo tanto, hay que discrepar con la opinión que entiende que el "bien sacrificado" solo puede ser uno que sea susceptible de ser objeto de derechos reales (De Trazegnies, 2001, p. 226). Por el contrario, conforme lo ha desarrollado nuestra Corte Suprema y Tribunal Constitucional, sobre la huella de la jurisprudencia de la Corte Interamericana de Derechos Humanos y el Tribunal Constitucional de Alemania, la propiedad en sentido constitucional, abarca cualquier derecho de tipo patrimonial, es decir derechos reales, derechos de créditos, etc. (SENTENCIA DEL VII PLENO CASATORIO CIVIL, fundamento III.4.1). En consecuencia, no hay razón alguna para considerar que solo son sacrificables los derechos reales. Los términos "bien sacrificado" del inciso 3 del artículo 1971, se tienen que interpretar en un sentido amplio. Si los derechos reales son sacrificables, pues otros derechos económicos también pueden serlo, en tanto que todo derecho patrimonial tiene el mismo "peso" frente a la Constitución.

Ahora bien, se puede decir que en materia de contratos el estado de necesidad no podría ser aplicable en rigor; puesto que lo correcto sería evaluar la aplicación del caso fortuito o la fuerza mayor. Lo que ocurre es que el caso fortuito o la fuerza mayor, de acuerdo a lo preceptuado en el artículo 1315 del Código Civil, tiene que ser "irresistible". Esta última característica, en cambio, no está presente en la configuración del "estado de necesidad". Son pues, conforme al diseño legislativo civil peruano, figuras distintas. Además, el caso fortuito y la fuerza mayor no requieren la presencia de un serio peligro de daño grave para el deudor, cosa que sí se requiere para la configuración del estado de necesidad. Y es que el caso fortuito y la fuerza mayor solo tienen que incidir en el cumplimiento de la prestación; en cambio, el estado de necesidad puede "atacar" a la persona del deudor, sin que necesariamente afecte las posibilidades materiales de cumplimiento. A mayor abundamiento, tomando en cuenta que la doctrina y jurisprudencia nacional dominante asumen la tesis de la unificación de la responsabilidad civil, no debería haber problema para considerar aplicable la normativa del "estado de necesidad" al régimen de responsabilidad del deudor (Espinoza, 2013, pp. 65-68).

En Alemania, la doctrina más autorizada ha aceptado que cabe sacrificar derechos de crédito para salvar derechos no patrimoniales. Empero, no ha apelado al § 904, sino a la categoría de la buena fe aplicada al cumplimiento de los contratos, prevista en el $\S 242$ del BGB. Y es que si bien se podría plantear una aplicación analógica del § 904, no debe pasar inadvertido que el BGB no tiene una regla como la prevista en nuestro inciso 3 del artículo 1971. El jurista alemán apela al principio de la buena fe, en tanto considera que no hay una regulación lo suficientemente precisa sobre esta materia, cosa que no sucede con nuestro Derecho Civil. Así, con base en la "buena fe", el derecho de crédito es sacrificado, tornándose en inexigible de forma parcial o íntegra, tal como se explica a continuación:

Hay, ciertamente, casos en los que un deudor tiene que estar facultado para denegar su prestación por ser ésta, de momento, «inexigible». Son aquellos en que están en juego consideraciones superiores; por ejemplo, el amor conyugal o maternal, la piedad, o incontestables deberes morales. Así, no es culpable la cantante que no actúa porque en el momento de la representación está agonizando su hijo o se entierra a su madre. No puede decirse que en este caso sea improcedente el deber de realizar la prestación. Antes bien, por ser la prestación inexigible, no puede reclamarse conforme al § 242 del Código civil, y el deudor puede denegarla (...) Consideremos el caso de un deudor que, por haber perdido inesperadamente sus medios de vida después de la guerra, no está en situación de pagar la 
renta convenida en toda su cuantía sin poner en peligro su propio sustento y el de sus parientes con derecho a alimentos, pero puede pagar parte de la renta o reanudar los pagos al cabo de cierto tiempo, cuando se haya procurado un nuevo y suficiente medio de vida. Su alegación de la transformación de las circunstancias sólo puede tener la eficacia de una excepción dilatoria para aquella parte de sus obligaciones que, según las circunstancias sobrevenidas, excede en aquel momento los límites de lo «adecuado». "Lo adecuado» es, en esta hipótesis, lo que, según las normas en que se funda el contrato, corresponda, conforme a la equidad, a las circunstancias de los interesados (Larenz, 2018, pp. 98, 165 y 166).

Nótese que se está haciendo referencia a obligaciones dinerarias. Como es sabido, en tanto que el género no ha perecido, es difícil postular que las obligaciones dinerarias devengan en propiamente imposibles. Es por esta razón que situaciones personales del deudor, en principio, poco o nada importan a efectos de sostener que la obligación dineraria haya devenido en imposible. Es por eso que la doctrina alemana, como acabamos de ver, para las guerras u otras hecatombes sociales, no postula la imposibilidad de ciertas obligaciones dinerarias, sino su inexigibilidad conforme a la buena fe; esto es, su sacrificio.

Esta manera de apelar a la buena fe, resulta reforzada con otra idea, también de la doctrina teutona: el "riesgo de la realidad social común". Sobre el particular, se ha dicho lo siguiente:

Atenerse al reparto de riesgos propio del tipo contractual o especialmente pactado en el contrato en casos de guerra sucesos similares a la guerra o acontecimientos políticos y de catástrofes naturales en general, es injusto según la actual conciencia jurídica (...) El riesgo de la realidad social afecta por igual a quienes toman parte en la misma vida social. Todo deudor ha de responder por sí de su solvencia Si un deudor, por la quiebra de su deudor, no puede pagar sus propias deudas, eso es asunto suyo. Cualquier desgracia personal ha de soportarla aquel a quien afecta. En cambio, esta máxima ya no responde a las convicciones jurídicas actuales cuando la desgracia surge de la realidad social común a ambos contratantes. El riesgo derivado de la realidad social tiene que ser soportado por la colectividad (Flume, 1998, p. 616).

Así las cosas, el operador jurídico peruano tiene que asumir que cabe incumplir un contrato, o sea sacrificar un derecho de crédito, en base a un "estado de necesidad" que ha tenido lugar por causa de la crisis socioeconómica generalizada derivada de la pandemia; esto será así siempre que el incumplimiento sirva para salvar un bien de carácter no patrimonial, esto es un derecho de la persona. Así es, no cabe duda de que el derecho de crédito, siempre patrimonial, tiene "notoria diferencia" con un derecho de la persona, como la vida o la salud, que están en juego en estos "tiempos pandémicos".

¿Pero la pandemia, en realidad, califica como un suceso que genera peligros imprevisibles? Como se recuerda, un sector de la doctrina peruana considera que el peligro de daño tiene que ser imprevisible. No obstante, es bueno dejar constancia de que no toda la doctrina piensa así; de hecho, la gran parte de la doctrina, hasta la europea ya revisada, no contempla la idea de imprevisibilidad como un factor a evaluar en los casos de "estado de necesidad". La letra de la ley tampoco exige que la imprevisibilidad sea un requisito a tomar en cuenta, como sí sucede con el caso fortuito, la fuerza o la excesiva onerosidad de la prestación (artículo 1440 del Código Civil peruano).

En todo caso, en otra sede, he analizado el tema con alguna amplitud, concluyendo-como no podía ser de otra manera- que la pandemia y sus efectos nefastos en toda la sociedad califican como extraordinarios e imprevisibles:

Es evidente que la pandemia del Covid-19 califica como un hecho extraordinario. Sostener que las pandemias virales "son parte de la historia del mundo" (como las devastadoras "peste 
negra" o "gripe española") y, por ende, ordinarias y previsibles, sería manejar un enfoque totalmente caduco, como el que manejó la Corte de Casación francesa en pleno siglo XIX o las cortes italianas de hace un siglo. La pandemia es un fenómeno claramente extraordinario, puesto que no forma parte del acontecer normal del mundo. Es más, en este caso tenemos una genuina pandemia de escala mundial, lo que hace que el evento pueda ser "más extraordinario" todavía. Una pandemia global, en definitiva, no puede ser parte del curso natural y corriente de las cosas. Y, conforme a lo ya expuesto, cumple sobradamente el requisito de afectar la vida de la "generalidad de las gentes".

La pandemia también puede entenderse como un suceso imprevisible. Hasta noviembre del 2019, por ejemplo, nadie tenía la menor idea de que al mes siguiente iniciaría la propagación del Covid-19 en la ciudad de Wuhan. De hecho, durante todo el mes de diciembre del 2019, dentro y fuera de China, no había una idea clara del alcance del poder infeccioso del virus (...) O sea, es obvio que ningún peruano "promedio" podría imaginar, durante enero del 2020, que tendríamos que vivir un aislamiento social obligatorio, pues eso no era claro ni para el jefe de la OMS, quien pone de manifiesto el carácter imprevisible del impacto socioeconómico del Covid-19 sobre un país como el nuestro (Ninamancco, 2020, p. 112).

Ahora bien, en relación al caso del literal a), si el inquilino (como en el ejemplo ya citado de la doctrina alemana) ha perdido sus ingresos por causa de esta "guerra sanitaria" contra la pandemia y tiene que elegir entre su subsistencia y pagar la renta, puede acudirse a la idea de "estado de necesidad" para sostener que se encuentra autorizado para no cumplir o solo cumplir de forma parcial, al amparo del inciso 3 del artículo 1971. Pero, nótese bien, siempre y cuando su salud o vida peligren seriamente. El arrendador tendría un "deber de tolerar" esta dura situación.

Mal se haría en pensar que la crisis financiera del inquilino es un asunto "personal" que no debe afectar a la obligación dineraria a su cargo. Si se puede verificar que la crisis deriva de las medidas de lucha contra la pandemia, sería una genuina broma de mal gusto sostener que tal crisis es un asunto "personal". Hay que tener en cuenta, de manera obligada, la idea de "riesgo de la realidad social común". El inquilino no padece una crisis "personal", sino que es una víctima más de la hecatombe que afecta a la "realidad social común". Por ende, el peligro no podría considerarse imputable por dolo o culpa al arrendatario. El arrendador, en todo caso, tendría que demostrar-cosa bastante peliaguda, por cierto- que el arrendatario se contagió de forma negligente. Las secuelas de la pandemia sobre los contratantes, en principio, son un asunto atribuible a la "sociedad" como un todo, no a una persona en particular.

Otro tanto cabe decir en relación al caso del literal b), el cumplimiento de las prestaciones no dinerarias puede ser sacrificado por el "estado de necesidad" del deudor. Si se aprecia que el deudor no cumplió porque debió atender a su familia o a sí mismo de cara a la enfermedad del Covid-19 (piénsese en el caso de tener que madrugar a diario para conseguir abastecerse de oxígeno, lo que deja al deudor con tiempo insuficiente para cumplir sus contratos), puede decirse que se prefirió un bien claramente "superior" al crédito de su contraparte contractual. Por el contrario, si la vida o la salud del deudor no están en juego y, pese a ello, no cumplió con las prestaciones contractuales, obviamente no cabe invocar el "estado de necesidad".

Y esto último tiene directa relación con el caso del literal c). Aquí, no es difícil apreciarlo, se puede complicar mucho la invocación del "estado de necesidad". Como ya se dijo, conforme a la jurisprudencia de nuestros máximos tribunales, los derechos patrimoniales tienen-todos- el mismo "peso" constitucional. Alegar razones económicas-por más "urgentes" que puedan ser- para incumplir un contrato, es pretender sacrificar "derechos económicos" a costa de otros "derechos económicos". Siendo así, no se cumple el requisito de la "notoria diferencia" entre el bien sacrificado y el bien salvado. No basta, es oportuno resaltarlo, una "diferencia" entre tales bienes; tiene que ser 
un diferencia "notoria". Podría decirse que la microempresa tiene una "urgencia mayor" que la de su contraparte contractual, pero esta circunstancia ya es ajena a los bienes ("derechos económicos") en sí mismos considerados. No se olvide que la "diferencia notoria" es entre los bienes, no entre las situaciones particulares de las partes.

Podría sostenerse que la microempresa pretende salvarse a sí misma, a costa del crédito de su contraparte. De este modo, la microempresa vale más que tal crédito. Pero, a decir verdad, demostrar esto es un tanto difícil. ¿Un solo crédito puede marcar la diferencia entre "la vida y la muerte" de una microempresa? Ahora bien, si el patrimonio de la microempresa termina siendo casi igual que el monto o el valor del crédito que pretende desatender, es claro que aquí sí podría decirse que un solo crédito podría marcar la diferencia entre "vivir o morir". No obstante, es claro también que no se configuraría el requisito de la "diferencia notable" entre los bienes.

Lo que podría alegar la microempresa son argumentos fundados en la imposibilidad o en la excesiva onerosidad sobreviniente de la prestación, invocando una lectura de la normativa respectiva en base a que estamos ante una circunstancia que afecta a la "realidad social común". En otro sede me he detenido al respecto (Ninamancco, 2020, pp. 99 y ss.), pero en lo que aquí respecta, se presenta mucha dificultad en plantear que la microempresa puede justificar el incumplimiento de sus contratos en razón de un "estado de necesidad". Es oportuno recordar que la doctrina europea sí se ha preocupado por subrayar la gran diferencia que debe existir entre el bien sacrificado y el bien salvado. Por un lado, los italianos han dejado de lado cualquier posibilidad de que el bien salvado sea un derecho patrimonial. Los alemanes, por su parte, precisan que el bien salvado tendría que ser "desproporcionadamente mayor" al bien sacrificado. O sea, una diferencia que puede entenderse como manifiesta o indudable. En este punto, el formante doctrinal europeo puede darnos una valiosa pauta interpretativa para entender a nuestra normativa en justos términos restrictivos.

\section{Estado de necesidad y desalojo "extrajudicial".}

Por último, queda por evaluar el caso del literal d). Aquí no aplicaría la lógica "contractual", pues se indicó que el poseedor es precario. Esto es que no tiene vínculo contractual (vigente) con el propietario del inmueble.

En términos simples, se tiene un caso donde el propietario trataría de salvar la vida o la integridad física de un familiar directo o cercano, a costa de sacrificar la posesión del precario. Visto así, sería claro que puede aplicar el "estado de necesidad". La diferencia entre los bienes es patente. Empero, deben hacerse tres precisiones que estimo relevantes:

i) El precario tendría que tener donde irse, pues tampoco cabría expulsarlo y exponer su vida o salud lanzándolo a la vía pública. Y este es un escollo grande para la configuración del "estado de necesidad" en este casos, pues-en realidad- el propietario trataría de salvar a la persona de su familiar a costa de la persona del precario. No se configura, entonces, el requisito de la "diferencia notable". Acá, el destino del precario es un asunto que sí le concierne al propietario.

ii) Si hubiera otra alternativa, reconocible por el propietario (recuérdese a la autorizada doctrina que señala que el error excusable no evita la configuración del "estado de necesidad"), para que el familiar pase la cuarentena a buen resguardo, no procedería este desalojo "extrajudicial". Recuérdese que nuestro Código Civil indica que el sacrificio del bien sacrificado debe ser "indispensable". Si el familiar pudo encontrar otro lugar para pasar la cuarentena, no cabe invocar el "estado de necesidad". De este modo, el apoyo de otros familiares y amigos, podría neutralizar la presencia de un supuesto de "estado de necesidad". Incluso, si se comprobara que el propietario tenía los medios económicos para conseguir un ambiente para su familiar, 
el estado de necesidad quedaría descartado. Otro tanto cabe decir del internamiento del familiar enfermo en algún centro de salud.

iii) El precario no podría repelar el accionar del propietario, fundándose en el artículo 920 del Código Civil, pues la actuación del propietario estaría amparada por el inciso 3 del artículo 1971. La tutela extrajudicial de la posesión opera, como bien sabido es, solo ante "agresiones" ilegítimas. Así pues, si el precario repele el "ataque" con éxito y luego se acredita que el propietario tenía acceso a otros medios para que su familiar atienda su necesidad de vivienda; pues el precario sí encontraría legitimado su accionar en el artículo 920. Si el "ataque" le generó daños, tendría derecho a solicitar una indemnización, pues sería un acto ilícito. Obviamente, si el propietario actuara amparado por el inciso 3 del artículo 1971 y el precario se resiste y causa daños, este tendría que asumir la correspondiente indemnización.

Queda mucha tinta en el tintero; pero toca ya cerrar esta aproximación. La pandemia nos exige discutir sobre figuras que, hasta hace poco, estaban un tanto olvidadas. Estas discusiones deben ser llevadas con serenidad y respeto, de lo contrario no serán genuinamente productivas. Y la productividad de la discusión, hoy más que nunca, es una necesidad insoslayable. Lo último que se necesita, en esta prueba de fuego para nuestro Derecho Civil y el ordenamiento jurídico en general, son "intérpretes" que se consideren dueños de la verdad. Los debates están abiertos y hay que tratar de seguir generándolos, en ese intento-como se advirtió al inicio- se enmarca este trabajo. Solo me queda agradecer al amable lector o lectora que me haya acompañado hasta aquí.

\section{RESEÑA BIBLIOGRÁFICA}

- Bianca, M. (2002). Diritto Civile. T. 5. La responsabilità. Milán: Giuffrè Editore.

- Brun, P. (2016). Responsabilidad civil extracontractual. Traducción de Cynthia Téllez Gutiérrez y Eduardo Cárdenas Miranda. Lima: Instituto Pacífico.

- Comisión Económica Para América Latina Y El Caribe - Cepal (2020). Informe sobre el impacto económico en América Latina y el Caribe de la enfermedad por coronavirus (Covid-19). Santiago de Chile: Naciones Unidas.

- De Trazegnies, F. (2001). La responsabilidad civil extracontractual. T. I. Lima: Fondo Editorial de la Pontificia Universidad Católica del Perú.

- Espinoza, J. (2013). Derecho de la responsabilidad civil. Lima: Editorial Rodhas. FERNÁNDEZ

- Cruz, G. (2019). Introducción a la responsabilidad civil. Lima: Fondo Editorial de la Pontificia Universidad Católica del Perú.

- Flume, W. (1998). El negocio jurídico. Traducción de José María Miquel González y Esther Gómez Calle. Madrid: Fundación Cultural del Notariado.

- Larenz, K. (2018). Base del negocio jurídico y cumplimiento de los contratos. Traducción de Carlos Fernández Rodríguez. Buenos Aires: Editorial Olejnik.

- Ninamancco, F. (2013). Embargo inscrito y tercería de propiedad. Lima: Editorial Gaceta Jurídica.

- Ninamancco, F. (2020). El Covid-19 y los contratos de arrendamiento: ¿es aplicable la excesiva onerosidad de la prestación? Gaceta Civil \& Procesal Civil Nº 82. pp. 99-118.

- Torres, A. (2014). Teoría general de las obligaciones. Vol. II. Lima: Instituto Pacífico.

- Westermann, H.; Westermann, H.; Gursky, K. Y Eickmann, D. (2007). Derechos Reales. Vol. I. Traducción de Ana Cañizares Lazo, José María Miquel González, José Miguel Rodríguez Tapia y Bruno Rodríguez Rosado. Madrid: Fundación Cultural del Notariado.

Fecha de recepción: 22 de mayo de 2020

Fecha de aceptación: 01 de junio de 2020 